\title{
MOOCs for Universities and Learners An analysis of motivating factors
}

\author{
Hugh Davis ${ }^{1}$, Kate Dickens ${ }^{1}$ Manuel Leon ${ }^{2}$, Maria del Mar Sanchéz Vera ${ }^{3}$ and Su White ${ }^{2}$ \\ ${ }^{1}$ Centre for Innovation in Technologies and Education, University of Southampton, Highfield, Southampton, UK \\ ${ }^{2}$ Web and Internet Science, ECS, University of Southampton, Highfield, Southampton, UK \\ ${ }^{3}$ Departments of Didactics and School Organisation, University of Murcia, Murcia, Spain \\ \{hcd,kate.dickens\}@soton.ac.uk,\{ml4c08,saw\}@ecs.soton.ac.ukmmarsanchez@um.es
}

Keywords: $\quad$ MOOCs, Education Disruption, Motivations for Learning, Institutional Strategy

\begin{abstract}
Massively Open Online Courses (MOOCs) are a recent introduction to the palette of educational offerings yet in a short time they have become the subject of massive interest and hype. There are those that predict that these free courses are the first ripple in the coming wave of disruption that the web and on-line education will cause to traditional universities. However University investments in producing MOOCs are increasing exponentially and at the same time learners are enthusiastically registering in their tens of thousands for these courses. This paper describes some research into the motivations for universities to create MOOCs and the motivations of learners in registering and completing them. Our results show a spectrum of motivations for universities, and suggest a need for individual universities to be clear of where they sit in that spectrum. For students we see that motivations can vary significantly across cultures.
\end{abstract}

\section{INTRODUCTION}

In September 2013 the first UK based MOOC platform, FutureLearn, announced its first batch of twenty MOOCs. These MOOCs ran in the final quarter of 2013 and included the University of Southampton's first MOOC "Web Science: how the web is changing the world". The research described in this paper was part of our attempt to answer the questions "why are we doing this?" and "why would the learners want to study MOOCs?"

These questions are worthy of discussion at a time when the landscape for higher education is widely predicted to change, as the result of the disruption caused, mainly by the way the web is changing the world! Reports such as Barber et al., 2013 predict that business models for higher education are about to collapse in much the same way that the music industry's business model collapsed in the 2000's; and possibly MOOCs are the Napster in this scenario. These predictions are being followed by real financial investment: text book publishers are rapidly re-inventing themselves as purveyors of on-line education, and lobbying government for a level playing field with universities; and venture capitalists are lining up at universities' doors trying to buy into a share of their more popular courses. Venture capitalists expect quick profits, so they are presumably banking on rapid disruption. If MOOCs are at the frontier of such disruption, then what is the motivation for universities to embrace them rather than resist them?

In 2013 many universities, for example in the in the UK FutureLearn Consortium, have been investing greater sums of money in developing single MOOCs (sums of $£ 30 \mathrm{~K}-£ 60 \mathrm{~K}$ are regularly quoted) than they have been accustomed to investing in the development of much longer courses. It is relevant therefore to ask what is the business model for universities in making this investment.

When it comes to student motivation for learning, teachers in higher education have insisted for years that learning is driven by assessment (e.g. Boud, 1995), and yet learners are registering for MOOCs in an enormously wide range of subjects in their tens of thousands. Clearly they are not motivated by grades since in most MOOCs there are no grades. So it is valid to ask why these students are so interested in studying MOOCs.

In carrying out our research on student motivation we wished to get beyond the survey of the set of students that completed a particular MOOC and to investigate some of the cultural differences in motivations, so our results are based on a survey circulated by social media within the UK, Spain and Syria. 


\section{METHODOLOGY}

As indicated above, our research is divided into two studies, looking at

1) Higher Education Institutions' (HEI's) motivations to create MOOCs.

2) Learners' motivations for participation

The two studies use different methodologies. Our research on the motivations for universities was carried out mainly as a meta-review of the literature, but is also informed by our experiences and discussions with FutureLearn partners.

For learners' motivations an online survey was conducted to gather information about those who had participated in a MOOC, looking in depth into the reasons why learners decided to register and eliciting some reflections on their beliefs, attitudes and behaviours when participating in a MOOC. The questionnaire was analysed primarily by using a quantitative method of frequencies of responses.

It might have been good to have surveyed a number of HEIs about their motivations, but at present this is a very competitive arena, and it would be difficult to ensure the veracity or completeness $f$ the responses that might be received. It is likely that this situation will change as the subject matures.

\subsection{Methodology: HEIs' motivations}

For HEIs' motivations a qualitative approach using content analysis was conducted across a set of around 60 articles to evaluate arguments about whether or not HEIs should foster MOOCs.

2012 was really the year in which many MOOCs became available, mostly through Coursera, edX and Udacity in the USA. These MOOCs have now been evaluated and we are now beginning to see many papers published, but at the time we began this research there were few academic articles and to track the emerging phenomena of MOOCs it was necessary to also observe the web-based grey literature of journalistic articles, blogs and social media.

\subsubsection{Identification and selection of sources}

Selected contributions published in three different domains, were used: namely education technology journals; HE magazines; and blog posts. The sources were identified by using different search strategies depending on the domain where the literature was published. For the peer-reviewed academic literature in journals, the method used was inspired by the identification of sources in the systematic literature review by Liyanagunawardena et. al. of MOOCs carried out in 2013. The journalistic and blog (grey literature) sources were drawn from the curated collections of four educational technologists via the Scoop.it social media site over the four months prior to August 2013. These MOOC-focused curations drew on a wide range of sources of which a more reduced number were in turn chosen for this project, seeding by provenance and perceived authority and encompassing views which were either for or against the adoption of MOOCs in HEIs. Sources were primarily selected according to their relevance to the topic of MOOCs in HEIs.

- Academic literature was used to identify the drivers of the emergence of MOOCs

- Grey literature was used for identifying current debates.

More rigour and credibility was credited to peerreviewed journal articles, than in journalistic pieces and blog posts. Therefore, the selection of the papers was focused on their content and relevance. The selection of grey literature placed greater emphasis on authorship and provenance because, as noted by Daniel (2012), the media contains abundant literature in which the intention of promoting MOOCs as products for profit seeking undermines the objectiveness of the judgements towards their potential to improve the education delivery.

\subsubsection{Analysis of sources}

Herring's (2004) adaption of Krippendorf's (1980) Content Analysis (CA) method for online context was used with the academic and journalistic corpora of MOOC related sources. Apart from identification and selection of sources explained above, CA involves establishing of categories into which the arguments in the sources are to be distributed. With academic sources, MOOCs were placed into three contexts in order to explain their emergence. These contexts were

a) open education movements;

b) the evolution of technology in distance education;

c) disruptive innovations in education.

Because they were more opinion loaded, nonacademic sources were classified into debates of sustainability, quality, and impact of MOOCs from an institutional perspective (for more information see Leon, 2013).

\subsection{Methodology: learners' motivation}

A MOOC heavily relies on the autonomy of the student to control their learning process. Termed "Self-regulated learning" (SRL), this concept which emerged in the 80 s addresses the question of how 
students manage learning process, and includes cognitive strategies, metacognition and motivation (Zimmerman \& Schunk, 2000). Motivation is an important part of SRL. Specifically, intrinsic motivation is needed to perform learning tasks as part of the forethought, the strategic process that precedes performance in learning (Barnard-Brak et al, 2011). Arguably, analysing the intrinsic and extrinsic motivation that leads a learner to take the decision to register in a MOOC is not easy, because there are many cognitive and affective components involved. However, it is more feasible to understand the reasons that may lead a person to consider undertaking a MOOC. The data was gathered through a questionnaire, from an empirical analytical perspective. The questionnaire contains 24 questions, grouped by the following themes:

About you. This section had the goal to obtain basic information about the participants: residence, age, gender, occupation, kind of learner.

Education. Focused on level of education and to know if parents attended University.

MOOC providers. To know if people had participated in any MOOC before, when it was, when and where they accessed to materials and what device they used for that.

Motivation. Related to know which MOOC platform have they used, how many MOOCs they have done, if they interacted with others, tools used in the MOOC experience, activities developed, and finally, questions related with reasons for starting a MOOC, and for abandoning it if that was the case.

The survey was designed and piloted. It was also translated into Arabic and Spanish, to obtain data from those language environments. The questionnaire was published using the University of Southampton web based survey tool iSurvey. The responses to questionnaire were elicited through Facebook, Twitter and email. Once the data was collected, it was analysed through SPSS software. The categorising and coding process of the variables for the questionnaire was related to the type of question (mainly nominal) and a direct reading of the data was made by frequency calculation.

\section{FINDINGS: MOTIVATIONS FOR HEIS}

\subsection{MOOCs in context}

The analysis of the two sets of sources generated a number of observations on the institutional motivations and reactions to MOOCs.
The main observations In terms of the established contexts of the emergence of MOOCs determined by the analysis of academic sources, were as follow:

Strategic Growth: Marshall, 2013, argues that developing MOOCs is part of HEI strategic plans to remain competitive in the market for learners seeking and affordable education balancing the 'bargaining power of buyers' and the 'bargaining power of [competitor HEI] suppliers'.

Marketing: Delarocas \& Alstyne, 2013 observe that MOOCs are often introductory courses which contribute to a recruitment marketing strategy aim to reach large numbers of MOOC learners as a means of targeting potential paying students

Strategic Collaboration: Universities are gathering in consortia around emerging MOOC platforms, such as Coursera and FutureLearn and EdX. The University of Edinburgh's report 2013 identified belonging to peer communities as a way to explore new educational methods, and secure greater reach and more presence for their courses.

Organic Growth / Evolution: Yuan \& Powell, 2013 argue that MOOCs emerge as a natural evolution of Open Educational Resources (OERs). HEIs especially those already championing OERs, such as Harvard and MIT are compelled to sustain Open Education within this new format.

Response to Learners: Castells influential 2011 analyses contemporary societies' emphasises use of available technologies to engage in networked interactions, in the 'networked society'. Williams et. al., 2012 observe that learners are not only ready to learn collaboratively through social media but also demand it. This trend has permeated the education domain, and leading HEIs must develop pedagogical approaches that fulfil these demands if they want to maintain their top positions in the rankings.

Learner Analytics: MOOCs produce large quantities of learner data. This is valuable data that can inform the design of enhanced, customised and effective instructional methods, which may in turn raise the perceived quality of tuition in universities, and hence improve competitiveness. Analysing these datasets can shed light on collective and individual learning processes and patterns (De Liddo et. al. 2011), learners' engagement levels in different course stages (Breslow et al, 2013), or their potential for success or failure (Barber \& Sharkey 2012).

Educational Enhancement: taken collectively the observations above also suggest that educational enhancement is either a sub-objective or a happy consequence of MOOC participation. 


\subsection{Main debates on MOOCs}

An extensive survey on the contemporary grey literature identified three areas of sustainability, quality, and impact in which the debates were more frequent and intense. Within sustainability two main themes occupied most of the debates, 1) analogies with other business initiatives; 2) learners' sustained participation.

The business analogy of sustainability championed by Marginson (2012), Young (2012), and the Economist (2013) draws parallels between MOOCs and successful business models of Silicon Valley initiatives such as Google and eBay, who made early investments, provided free services, and now make substantial profit. Weston, 2012 presents another side of the debate citing the experience of companies who suffered the dotcom bubble; Ptascynsky, 2013 suggests that universities will realise that they do not external platforms to run MOOCs, since universities can provide fairly feasible technological solutions without the need of third parties.

The sustainability of learners' participation, debate has optimist commentators such as Lawton \& Katsomitros, 2013 arguing that high numbers of enrolling students provide an opportunity for novel sustainable business models whereby some costs are met by institutions, governments and future employers while students pay for assessment and certification.

However, the interpretation of the high drop-out rates is contentious and relate to the quality of provision as well as sustainability. Sceptics like Tauber, 2013 see them as a serious issue rooted in a poor conceptualisation and design. Kollowitch 2013; 2013a illustrates the failure of MOOC models with concrete examples, such as the bad experiences with MOOCs of Colorado State University and San Jose State University. However Catropa, 2013 counters this sceptical view as a mistake of underestimating the high number of students who actually complete a MOOC despite the high drop-out rates and Parr, 2013 claims it ignores the fact that many learners who do not complete a MOOC still benefit from it.

There were frequent debates in the media regarding the quality of MOOCs. Sceptics see them as not being able to reproduce the discussions that takes place in small face-to-face group settings, which are deemed as the only way meaningful learning can take place (Rheingold, 2013; Brighouse, 2013). A frequent counterargument is that seminar discussions can and have been reproduced successfully in web-based experiences (Davidson, 2013). Also, many recognise that MOOC tuition quality might be lower due to the ratio of students to teacher, but it is still reasonable for those who will otherwise not access HE (Horn, 2013).

A further motivational factor to HEI involvement in MOOCs is their impact and spread. Lewin, 2012 compares it with a tsunami; the more universities join the movement, the more universities will be urged to join it. This tsunami will fuel a revolution in HE. However, sceptical views, such as that of Drezzner (2013), situate the current enthusiasm in the beginning of a hype cycle that will soon deflate.

\subsection{MOOCs as Distance Education}

The literature identifies six distinct generations of distance education associated with the role of technology in each step: (Nipper, 1989, Taylor, 1995, 2001; Fozdar and Kumar, 2007; Caladine, 2008) MOOCs can be considered alongside this timeline.

First generation: a "correspondence model", studying via mail.

Second generation: incorporated technologies such as video.

Third generation: combining tools and telecommunications (Nipper, 1989), also referred to as "telelearning", e.g. incorporating the use of videoconferencing. It is also the moment when educational concepts as "open education" and "flexible learning" emerge

Fourth generation: "the flexible learning model" Taylor (1995) emphasises the use of technology and the Internet in the $90 \mathrm{~s}$ from different Universities, with the first eLearning experiences.

Fifth generation: adds the emergence of Virtual Learning Environments (VLE), the use of Virtual Campus and resources processes characterized by automation systems (Taylor, 2001).

Sixth generation: based on Web 2.0, like a model of progress of interactive environments. (Caladine, 2008). Blogs, wikis and social networks have changed the way people use the Internet, and represent new opportunities to learn.

Perhaps MOOCs will become the seventh generation in distance education. Clearly they enact a model of distance education. The current "boom" in the university narrative created by MOOCs suggest some turning point in distance education. Although perhaps in terms of a formalized educational understanding of MOOCs it is rather early to make that claim. 


\subsection{Structure and Assessment in MOOCs}

Two distinct kinds of MOOC are widely recognised: xMOOCs and cMOOCs. The xMOOCs focus on course content and are typically located on a single web platform which provides access to the contents. cMOOCs are related to connectivistm incorporating the design and realisation of networked learning and based on the ideas of Siemens (2012a, 2012b) They start from the idea that we learn when we connect with other people, accordingly cMOOCs manifest in a more open format working with social and collaborative tools.

In early MOOCs, the opportunity provided by participating in a MOOC was not to primarily obtain a certificate, but to learn. This aspect of cMOOCs is highlighted because "participation in a MOOC is emergent, fragmented, diffuse, and diverse. There is no credit or certificate offered for completion" (McAuley et al, 2010).

More recently, many MOOCs, particularly, xMOOCs, offer certification (free or charged), providing participants the chance to formally record their learning and thereby to improve their CV. O'Toole, 2013, in a discussion paper looking at peer assessment, asserts that "whereas in the cMOOC participants are primarily interested in building the collective capabilities of the whole network, and hence are more likely to use feedback and ratings systems honestly, in xMOOCs participants are aiming to get a good personal grade". A demand for validated certification exists and some companies are beginning to sign agreements with institutions to provide MOOC participants with such services e.g. the agreement between Udacity and Pearson to create a network of assessment centres, and a similar agreement between Miriadax, the Spanish MOOC platform and Telefonica.

\section{FINDINGS: MOTIVATIONS OF LEARNERS}

\subsection{Findings}

A total of 258 questionnaires were completed: 52 English, 193 Arabic, 40 Spanish. The majority of respondents were in the 18-24 age range there are variations depending on the survey language identified throughout the survey. Male respondents formed the majority $(72.5 \%)$. We note that this sample may not be typical of the MOOC learner community as it has so far emerged in the USA and UK, where typical figures indicate roughly equal participation across the age range and genders. We assume that the method of distributing the survey may have had an effect.

Table 1: The majority of respondents were male.

$\begin{array}{ll}\text { English } & 67.3 \% \text { male } \\ \text { Arabic } & 77.2 \% \text { male } \\ \text { Spanish } & 48.7 \% \text { male }\end{array}$

When participants were asked about the platform, figure 1 , Coursera leads by far over other platforms. However, this percentage is higher in the English questionnaire than in the rest. It is important to note that close to the $25 \%$ of those who answered the questionnaire in Spanish identified a platform tailored to Spanish language MOOCs called Miriadax, Similarly Arabic respondents indicated a range of other platforms, such as the Virtual Syrian University. (Note that at the time of this survey, FutureLearn had not yet launched).

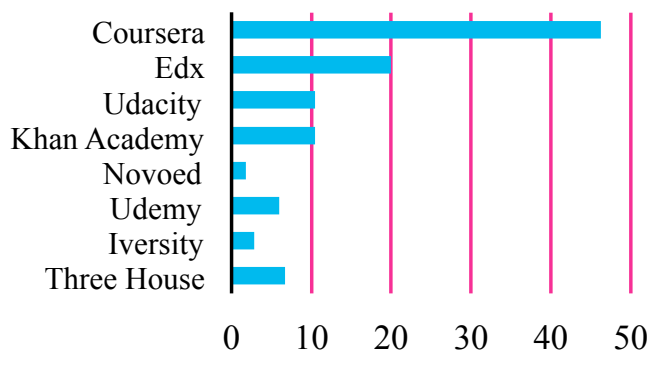

Figure 1: MOOC platform used

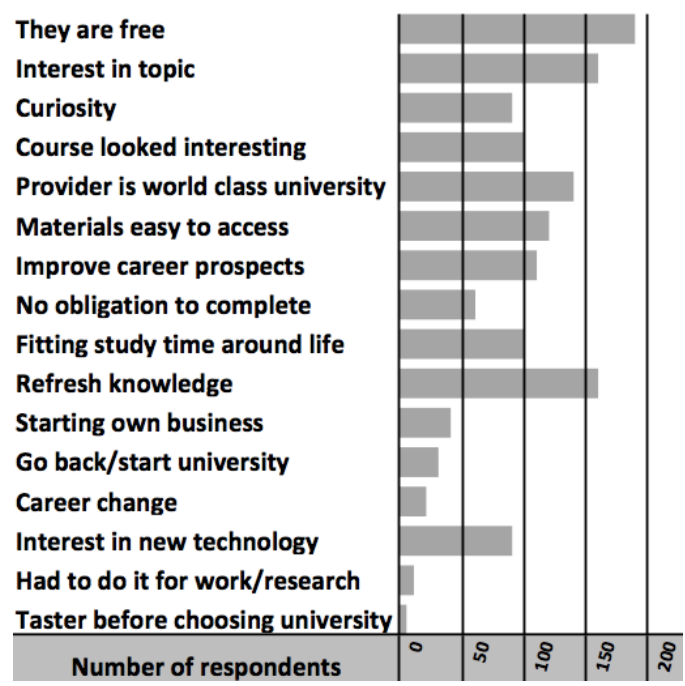

Figure 2: Distribution of responses about motivation 
A large volume of interesting data have been obtained from this questionnaire, however, the remainder of this paper will focus on motivation related data, concentrating on reasons that that led respondents to participate in a MOOC. In this section, respondents could choose from a number of options and could check more than one. Carefully analysing these data, a number of reasons normally found in the web and scientific discussions, appear to be confirmed. Figure 2 shows all options:

The following analysis explores the findings, indicating whether or not they underpin, widely perceived motivations behind learners on MOOCs.

\subsubsection{MOOCs are free and open}

Free availability is the important factor according to the survey selected by $67 \%$. A particularly high number of respondents from the Spanish questionnaire selected this option $(72.5 \%)$.

Providing educational resources for free is not a new and open licensing for software, resources and learning objects is well established. MIT launched the Open Course Ware project (OCW), in 2001 to share web-based teaching materials under Creative Commons licenses. The main difference between MOOCs and OCW is that while initiatives like OCW focus on sharing teaching materials, Universities are using MOOCs to realise a complete learning process. Learners are not only able to access the material, but they can also follow lessons, develop activities, talk with online-classmates, and even be evaluated, all for free and usually open.

If freeness is a fundamental aspect that motivates students to follow a MOOC, and it would be interesting to know which aspect of this is most relevant to them.

\subsubsection{MOOCs are convenient: fitting around life}

There are clear differences in motivation related to fitting study time around your life, in general, this selection is not chosen by a lot of people (36\%), but it is of interest. The Arabic responses show 27.5\% interested in this aspect, the Spanish represents $65 \%$. The majority of Spanish participants were in full time employment which may be the reason that they rate this aspect as relevant.

\subsubsection{MOOCs update knowledge and improve CVs}

The question A MOOC helps to improve a CV: appears more related to the need for certification to be shown in a $\mathrm{CV}$. In the survey, improving $\mathrm{CV}$ was selected by $54.4 \%$ of all participants as one reason to use the knowledge in a MOOC, but this percentage rose to $61.7 \%$ of Arabic participants, probably because the majority were students. This is consistent with other studies, for example in the study by Duke University (Belanger \& Thornton, 2013 this is been highlighted as the main reason students participated. A MOOC helps to update knowledge: has been highlighted by many as very relevant and motivation. Specifically $59.1 \%$ of Arabic and $70 \%$ of Spanish participants said that one main reason to do a MOOC is to refresh knowledge.

\subsubsection{MOOCs build a social learning community}

MOOCs may have social components that motivate learners to register to participate. Some $55.8 \%$ of respondents affirmed they were the first among acquaintances, family, colleagues and friends to participate in a MOOC. However 124 respondents from 285 found out about MOOCs via social media and then decided to participate. MOOCs can represent an opportunity for socialization. Online community has become increasingly important in the Internet user's life. Web 2.0 tools (blogs, wikis, social networks) make the Web as a place to develop social community where participation is important.

\subsubsection{MOOCs satisfy interest and are useful}

In a market with a lot of options, MOOCs can represent a new way to learn and access to interesting digital content. Interest in the topic is one important reason for participating in a MOOC, $56.8 \%$ overall. English respondents showed the highest preference with $80 \%$ of English respondents selecting this aspect.

Usefulness also features; $60.6 \%$ of participants overall declared they would use the knowledge gained during the MOOC in a personal project, and $63.2 \%$ in personal development These data follow the same line as other research, such as Duke University, in North Carolina, USA, which found that interest in the topic was identified by $87 \%$ of the students as a motivational aspect (Belanger \& Thornton, 2013). In this same study, many students indicated that they thought the course would be fun and enjoyable. This aspect of 'edutainment' where usefulness and fun intersect may be of real importance.

\subsubsection{MOOCs enable learning with the best}

The origin of MOOCs in prestigious Universities, or by the effort of high profile or world leading academics may explain their apparent popularity and 
rapid growth and their power to attract the attention to many different learners. Although not quite the majority, about half the respondents, 48.1\%, identified 'provider was a word class university' as a reason for participation. The power of some Universities is apparent. There is some difference by origin of respondents. English respondents show the least interest at 38.5\%; Spanish 43\%; Arabic 51.8\%.

\subsubsection{MOOCs provide professional development and lifelong learning}

The University of Edinburgh report summarising of the experience of their six Coursera MOOCs in May, 2013 observed "In general, we attracted adults with high educational attainments". That is reflected in the survey 208 of the 282 have a degree (mainly undergraduate 133 of 285 . There are more postdoctorate learners in English and Spanish than in Arabic respondents.

The largest represented age range $(50,5 \%)$, is between 18 and 24 but there are a lot of differences depending on the scope: most Arabic users are in the range of 18-24 years old, this percentage decreases in English and even more so in the Spanish results, in where the largest represented age range is the 25 34 years old.

Motivations for 18 to 34 years may be closely related to the opportunity to improve their career, and moreover, enhance their professional network. Half the respondents indicated that participating in a MOOC enabled them to enhance their professional development and improve their knowledge in the workplace. Among Spanish participants the percentage identifying this as an important factor rises to $77.5 \%$

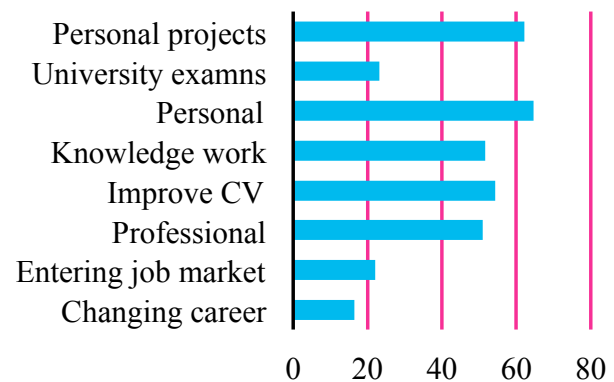

Figure 3: How will you use the knowledge gained during your MOOC

The survey asked how respondents would use the knowledge gained in the MOOC (figure 3). The most widely identified factors were personal development and projects. In a world increasingly multidimensional and diverse, MOOCs can work in Universities as a piece of the system providing open learning opportunities forming part of the learner's personal learning network. Professional and personal development needs are increasing alongside rapid business change. Therefore, MOOCs can offer a learning opportunity for people to develop life long learning.

\section{ISSUES}

\subsection{Pedagogic possibilities or illusion?}

The UK Department for Business, Innovation and Skills published a report in September 2013 reviewing the MOOC literature. They identified two trends in educational press, blogs and general media. One enthusiastically promoting MOOCs and reporting positively on learning experience and innovative forms of pedagogy, focusing on concepts like collaboration and community. A second sceptical view focussed on two fundamental flaws: the supposed benefits of MOOCs are the victory of content packaging; and the MOOC format itself is exclusive and does not have enough quality to develop skills in learners.

Educational technologists have spent years arguing that learning online is not only about content. In 1995 Bates suggested that open and flexible education should consist of the provision of flexible learning, built around geographical, social, and time constraints of each student, instead of being built around educational institutions' needs. The opportunity offered by the Internet for teaching and learning is change enable learning opportunities within flexible models, How can a MOOC, developed for hundreds or thousands of students, meet these aspirations? Educationally, MOOCs are only a small part of the multiplicity of wider international University systems. They cannot be assumed to be the panacea that will solve all educational problems.

Moreover, the very high drop out rate behind MOOCs is widely recognised. Clow et al. (2013) categorise that phenomena as "the funnel of participation". The funnel consists of four stages of participation: awareness; registration; activity and progress. What is not know is the extent of the participants satisfaction with the their (perhaps very limited) participation. However, "bad experiences" with MOOCs have been reported. In July 2013 "Inside Higher Ed" reported that, after six months of high-profile experimentation, San Jose State University plans to "pause" its work with Udacity, because "preliminary findings from the spring 
semester suggest students [in online joint Udacity/San Jose courses] do not fare as well as students who attended normal classes".

\subsection{Assuring assessment for learning}

The volume of learners in MOOCs perhaps inevitable makes feedback and the assessment two highly debated aspects MOOCs. In general, before MOOCs, assessment in learning online was a challenge for educators, mainly because it is an area that has seen little change. MOOCs are demonstrations of assessment online and at scale. Since technologies allow focus upon and tracking of the student learning process, e-assessment need not be an action that occurs only at the end of the course. However, taking into consideration skills and other aspects of the learning process, there is a lack of systems that facilitate a complete assessment, (Strither, 2002; Driscoll, 2007; Radenkovic et al, 2010).

Another desirable and thus important aspect of the learning process is feedback, assessment for learning. Feedback on assessment online is not always integrated in the mechanisms that assess students. It is challenging in a MOOC environment to develop effective assessments where, feedback reinforces learning and identifies inconsistencies in the learner process,

Additionally, the "massive" (independent and remote) nature inherent to MOOCs, makes it more difficult to develop high quality assessment. Although some MOOCs incorporate "peer assessment", O'Toole (2013) notes that, rather than peer assessment, it should be called "peer-grading", since it cannot be assumed that an equal or adequate level of understanding about assessment is possessed by all MOOC learners.

\subsection{Costs - benefit or risk?}

MOOCs are in principle free for students, although some platforms now incorporate a fee for a certificate of participation. MOOCs are not free for institutions. Universities have to invest time and money designing and uploading materials, managing the course, providing feedback. It is not clear if this model is sustainable over the time.

Luján (2012) discusses an interesting perspective that the most important American universities may be using MOOCs to protect themselves against a possible outbreak of "the bubble of Universities". This stresses the hypothesis that a MOOC can work for universities as an initiative to contain costs and enrol more students, thus obtaining more revenue and helping to resolve the crisis in the sector

Yuan and Powell (2013) suggest that companies may want to invest in MOOCs in order to enhance the company brand or a route to a new income stream from Higher Education business. Such motives may lie behind some companies signing agreements with institutions to provide services to MOOCs, such as the contract between Pearson and Udacity to create a network of evaluation centres.

\subsection{Widening inequalities}

MOOCs can create inequalities at different levels: among students, across educators, between institutions, and even at a global level. Regarding students, Cookson (2013) points out that job seekers with MOOC certificates will pose weak competition to those with traditional degrees. Carlson \& Blumerstyk (2013) note that the skills needed in a tertiary sector driven economy such as talking in public or business etiquette can only be acquired through face-to-face tuition. Those who most need these skills are the most disadvantaged, mainly due to their social backgrounds, and MOOCs may not be able to empower them.

Educators can also face inequalities following a massive adoption of MOOCs. While scalability could allow an elite of 'superstar' professors reaching massive audiences, it may leave the rest of educators in precarious conditions (Engler, 2013).

At institutional level, universities that can afford the costs of engaging in MOOCs may leave competitor institutions with little market share, as massive uptake could lead to centralisation. Although widely contested, Sebastian Thrun's prediction that only a few universities would be needed in the world (Leckart, 2012) should not perhaps be taken lightly.

Finally, at a global level, Sloep (2013) explains that, far from promoting inclusion, MOOCs promote cultural imperialism, because "developing countries lack the financial and human resources to develop an educational system of high quality, so when they confronted with MOOCs they cannot afford the luxury of refusing them".

\subsection{Learners' digital competencies}

From the first reports about MOOCs (Group MOOC, 2013; Osvaldo, 2013) a clear profile of learners that participate in MOOCs emerges; postgraduates and professionals. Brown (2013) points out that perhaps others e.g. undergraduate 
students are unlikely to possess the skills needed to be an autonomous learner in a MOOC.

Although such skills may be a prerequisite to effectively participating in MOOCs a wide range of people that do not have such skills can and do enrol. It would be interesting to investigate if the dropout found in MOOCs could be in part explained for the fact that there are people who register but they feel later they are not able to follow it for lack of skills.

\subsection{Certification to overcome plagiarism?}

Plagiarism is another issue to be borne in mind for a number of reasons. Firstly, if certification and accreditation are to become a significant part of the MOOC business models, the certificates issued by HEIs need a credibility that might be undermined by potential academic integrity breaches easily achieved from the anonymity of the web.

Also, the concept of plagiarism is not the same in all cultures. As Wilkinson notes (2008) students in certain Asian countries do not see plagiarism as an academic integrity breach, but as a way to show respect to the authority of the content producer. Therefore, universities not only should incorporate plagiarism detection software in their MOOCs, but also emphasize and clarify the principles of academic integrity expected in their programmes.

\section{SUMMARY AND DISCUSSION}

This paper has examined the motivations of institutions for making MOOCs and the motivations of learners for registering and completing them. It is clear that these are not simple matters so it is not surprising that there are no simple answers. However there are some useful understandings that we gained from our studies, surveys and interactions with other MOOCers that should be borne in mind when considering motivations.

When it comes to considering institutions' motivations to produce MOOCs, we need to understand that institutions are very much aware of predictions for the way the learning landscape will change with the disruption caused by on-line learning; forward thinking institutions believe that they need to be agile and respond to these changes.

Creating MOOCs can be seen as a way of enhancing the institution's reputation, not only in the subject area of the MOOC, but also in the area of quality on-line learning. Furthermore, internally, in the university, the enthusiasm and skills that go into producing MOOCs are the same that are needed to grow internal capacity for engaging with and producing quality on-line learning courses.
In the near future we may expect to see much softer dividing lines between accredited courses and MOOCs, on-campus education and off-campus education as universities start to make use of their MOOC materials to add value to their accredited courses, and in the extreme to produce whole programmes based on MOOC materials, as we starting to see with, for example, the Georgia Tech Computer Science MSc.

From the point of view of learners there would appear to be two important groups - those that see doing MOOCs as a form of Edutainment; perhaps an alternative to TV for the more discerning adult while another group are those that are seeking educational improvement for the sake of improving their career and life prospects.

MOOCs come in for much criticism for the high drop out rates, with only a small percentage of starters completing the course. But we need to be aware that the motivations of those who register for MOOCs are diverse and may be very different from those who register for University programmes. For a start, many who register may have no intention of finishing - they are equivalent to forum 'lurkers' those who just want to have a look inside the course, and the only way to do this is often to register. Secondly, the many users who sign up motivated by the edutainment will have a very different attitude to perseverance if the course turns out to be less interesting, more time consuming or harder than they had expected, than if they were signed up, at a personal cost, to a course that they believed to be critical to their future.

Finally, we should not assume that all learners intended to complete the whole course. Many learners may only be interested in part of the course, or may have time constraints that they knew when they started that would not enable them to complete the course. Nevertheless, since MOOCs are free and there is no penalty for failure to complete, many learners are enabled to drop in (and out) of courses at their own convenience. This should be a cause for educational celebration rather than criticism and represents learner choice and independence.

The authors are currently conducting further research jointly with the UK Higher Education Academy (HEA) attempting to identify the different behaviours and patterns that emerge from the range of motivations that learners express.

\section{ACKNOWLEDGEMENTS}

The authors would like to acknowledge the work and enthusiasm of Olja Rastic Dulborough and Maraim Masoud two students who worked on 
internships in the Centre for Innovation in Technologies and Education (CITE) for the summer vacation of 2013. We would also like to acknowledge the respondents who freely gave time to reply to our survey.

\section{REFERENCES}

Barber, M., Donnelly, K., Rizvi,S., and Summers.L., An avalanche is coming: Higher education and the revolution ahead. Institute of Public Policy Research (2013)., http://hdl.voced.edu.au/10707/247391

Barber, R., \& Sharkey, M., 2012. Course correction: using analytics to predict course success. In Proceedings of the 2nd International Conference on Learning Analytics and Knowledge (pp. 259-262). ACM.

Barnard-Brak, L., Lan, W.,L., \& Osland, V., 2010. Profiles in self-regulated learning in the Online Learning Environments. In International Review of Research in Open and Distance Learning, 11 (1).

Bates, A.W., 1995. Technology, e-learning and distance education. Routledge: Oxon

Belanger, Y., \& Thornton, J., 2013. Bioelectricity: a quantative approach. Duke University's first MOOC. (pp. 1-21)

http://dukespace.lib.duke.edu/dspace/bitstream/handle/ 10161/6216/Duke_Bioelectricity_MOOC_Fall2012.pd $\mathrm{f}$

Boud, D., 1995 Assessment and learning: contradictory or complementary. In Assessment for learning in higher education. pp 35-48.

Breslow, L.B., Pritchard, D.E., DeBoer, J., Stump, G.S., Ho, A.D., \& Seaton, D.T. 2013. Studying learning in the worldwide classroom: Research into edX's first MOOC. In Research \& Practice in Assessment, 8, 1325.

Brown, S. 2013. MOOCs, OOCs, flips and hybrids: the new world of higher education. In ICICTE 2013. Proceedings (pp. 237-247)

http://apps.webofknowledge.com/full_record.do?produ ct=UA\&search_mode $=$ GeneralSearch\&qid $=1 \&$ SID $=W$ 1xAnAorTZUmTypaXSZ\&page $=2 \&$ doc $=14 \&$ cacheurl FromRightClick $=$ no

Caladine, R. 2008. Enhancing e-learning with media.rich content and interactions. Hershey-New York: Information Science Publishing.

Castells, M. 1996. The rise of the network society: The information age: Economy, society, and culture (Vol. 1). Oxford: Blackwell

Catropa, D., 2013. Big (MOOC) Data. Inside Higher Education.

http://www.insidehighered.com/blogs/stratedgy/bigmooc-data

Cookson, P 2013 Are MOOCs the Answer? Preserving Value of Higher Education. The Quick and the Ed.
Posted on 23 August 2013 http://www.quickanded.com/2013/08/are-moocs-theanswer-preserving-the-value-of-higher-education.html

Daniel, J., 2012. Making sense of MOOCs: Musings in a maze of myth, paradox and possibility. In Journal of Interactive Media in Education, 3. http://jime.open.ac.uk/2012/18

Davidson, K. 2013. Clearing up some myths about MOOCs. Hastac. http://www.hastac.org/blogs/cathydavidson/2013/06/11/clearing-some-myths-aboutmoocs

Department for business, Innovation \& Skills 2013. The maturing of the MOOC: literature review of massive open online courses and other forms of online distance learning.

UK. https://www.gov.uk/government/uploads/system/uploa ds/attachment_data/file/240193/13-1173-maturing-ofthe-mooc.pdf

De Liddo, A., Shum, S. B., Quinto, I., Bachler, M., \& Cannavacciuolo, L. 2011. Discourse-centric learning analytics. In Proceedings of the 1st International Conference on Learning Analytics and Knowledge (pp. 23-33). ACM.

Dellarocas, C., \& Van Alstyne, M. 2013. Money models for MOOCs. Communications of the ACM, 56(8), 25 28.

Drezner, J. 2013. Twilight of the MOOCs? Foreign Policy. http://drezner.foreignpolicy.com/posts/2013/07/22/twil ight_of_the_moocs

Driscoll, M. 2001. Buildind better e-assessment, in Learning circuits, ASTD. http://www.astd.org/LC/2001/0601_driscoll.htm

Economist 2013 .The attack of the MOOCs. The economist Higher Education.

http://www.economist.com/news/business/21582001army-new-online-courses-scaring-wits-out-traditionaluniversities-can-they

Engler, C. 2013 MOOCs and Megatrends: A Prediction Comes True. Evolllution.

http://www.evolllution.com/distance_online_learning/ moocs-megatrends-prediction-true/

Herring, S. C. 2004. Content analysis for new media: Rethinking the paradigm. In New research for new media: Innovative research methodologies symposium working papers and readings (pp. 47-66). University of Minnesota School of Journalism and Mass Communication.

Horn, D. (2013) Failing fast, not spectacularly. Clayton Christiensen Institute for Disruptive Innovations. http://www.forbes.com/sites/michaelhorn/2013/08/15/f ail-fast-not-spectacularly/

Inside Higher-ED. 2013. Udacity Project on "pause". http://www.insidehighered.com/news/2013/07/18/citin g-disappointing-student-outcomes-san-jose-statepauses-work-udacity 
Fozdar, B.I and Kumar, L.S. 2007. Mobile learning and student retention, in International Review of Research in Open and Distance Learning, 8(2).

Group, Mooc. 2013. MOOCs @ Edinburgh 2013: Report \#1 Edinburgh: The University of Edinburgh. http://www.era.lib.ed.ac.uk/handle/1842/6683

Kolowich, S. 2013. How edX plans to earn, and share, revenue from its free online courses. The Chronicle of Higher Education http://chronicle.com/article/How-EdX-Plans-to-Earnand $/ 137433$

Kollowitch, S. 2013a. The MOOC 'Revolution' May Not $\mathrm{Be}$ as Disruptive as Some Had Imagined. The Chronicle of Higher Education. http://chronicle.com/article/MOOCs-May-Not-Be-SoDisruptive/140965/

Krippendorff, K. 1980. Content Analysis: An Introduction to Its Methodology. Newbury Park, CA: Sage

Lawton, R; Katsomitros, L. 2013. MOOCs and disruptive innovation: The challenge to HE business models. The Observatory of Borderless Higher Education. http://www.obhe.ac.uk/documents/view_details?id=92 9

Leckart 2012. The Stanford Education Experiment Could Change Higher Learning Forever. www.wired.com/wiredscience/2012/03/ff_aiclass/

León, M. 2013. Reactions on the Emergence of MOOCs in Higher Education https://eprints.soton.ac.uk/cgi/users/home?screen=EPri nt::View\&eprintid=358803

Lewin, T. 2012. Instruction for masses knocks down campus walls. New York Times. http://www.nytimes.com/2012/03/05/education/moocslarge-courses-open-to-all-topple-campuswalls.html?pagewanted $=$ all\&_ $r=0$

Liyanagunawardena, T. R., Adams, A. A., \& Williams, S. A. 2013. MOOCs: A systematic study of the published literature 2008-2012. In The International Review of Research in Open and Distance Learning, 14(3), 202227.

Luján, S. 2012. Preguntas y respuestas: ¿Qué son los MOOCS?

http://desarrolloweb.dlsi.ua.es/cursos/2012/que-sonlos-moocs/preguntas-respuestas

Marginson, S. 2012. Online open education: Yes, this is the game changer. The Conversation. $\mathrm{http} / /$ theconversation.com/online-open-education-yesthis-is-the-game-changer- 8078

Marshall, S. J. 2013. Evaluating the Strategic and Leadership Challenges of MOOCs. In MERLOT Journal of Online Learning and Teaching, 9(2), 216227.

McAuley, A., Stewart, B., Siemens, G. y Cormier, D. 2010. The MOOC model for digital practice. University of Prince Edward Island. http://www.elearnspace.org/Articles/MOOC_Final.pdf
Nipper, S. (1989). Third generation distance learning and computer conferencing. In R. Mason \& A. Kaye (Eds.), Mindweave: Communication, Computers and Distance Education. Oxford: Pergamon.

Osvaldo, C. 2012. MOOCs and the AI Standford like Courses: Two successful and distinct course formats for massive Open Online Courses. In European Journal of Open, Distance and E-Learning. http://www.eurodl.org/?article $=516$

O’Toole, R. 2013. Pedagogical strategies and technologies for peer assessment in Massively Open Online Courses (MOOCs). University of Warwick. http://wrap.warwick.ac.uk/54602/7/WRAP_O\%27toole ROToole

Parr, C. 2013. Mooc completion rates 'below 7\%. Times Higher Education http://www.timeshighereducation.co.uk/news/mooccompletion-rates-below-7/2003710.article

Ptaszynsky, J. G. 2012. MOOCs: The New Internet Bubble in Education? Microsoft Partners in Learning. $\mathrm{http} / / /$ pil-tei.com/blog/moocs-the-new-internet-bubblein-education/

Radenkovic, S., Krzavac, N. \& Devedzic, V. 2010. An assessment system on the Semantic Web, in Devedzic, V. \& Gasevic, D. (ed.), Web 2.0 and Semantic Web, annals of information systems. USA: Springer.

Rheingold, H. (2013) MOOCs, Hype, and the Precarious State of Higher Ed: Futurist Bryan Alexander. DML Central. $\quad \mathrm{http}: / /$ dmlcentral.net/blog/howardrheingold/moocs-hype-and-precarious-state-higher-edfuturist-bryan-alexander

Siemens, G. 2012a. Massive open online courses as new educative practice. http://es.slideshare.net/gsiemens/open-online-coursesas-new-educative-practice

Siemens, G. 2012b. What is the theory that underpins our MOOCs?

http://www.elearnspace.org/blog/2012/06/03/what-isthe-theory-that-underpins-our-moocs/

Sloep, P. 2013. MOOCs, what about them? Some moral considerations. In Stories to TEL http://pbsloep.blogspot.nl/2013/01/moocs-what-aboutthem-continued.html

Strither, J.B. 2002. An assessment of the effectiveness of e-learning in corporate training programs, in The international review of Research in Open and Distance Learning, vol.3, n.1 http://www.irrodl.org/index.php/irrodl/article/viewArti cle $/ 83 / 160$

Tauber, T. 2013. The dirty little secret of online learning: Students are bored and dropping out. Quartz http://qz.com/65408/the-dirty-little-secret-of-onlinelearning-students-are-bored-and-dropping-out/

Taylor, J. 1995. Distance education technologies: the fourth generation, in Australian Journal of Educational Technology, vol. 11(2). 
Taylor, J. 2001. Fifth generation distance education, in Higher Education Series, report n.40. Canberra, Australia:Department of Education, Training and Youth Affairs.

Washington Post. 2012. Santorum: Obama is "a snob" because he wants everybody in America to go to college". http://www.washingtonpost.com/blogs/postpolitics/post/santorum-obama-is-a-snob-because-hewants-everybody-in-america-to-go-tocollege/2012/02/25/gIQATJffaR_blog.html

Weston, C. 2012. MOOCs and other ed-tech bubbles. Ed Tech Now http://edtechnow.net/2012/12/29/moocsand-other-ed-tech-bubbles/

Wilkinson, L. R. 2008. ESL academic writing and plagiarism. In The Internet TESL Journal, 14(7).
Williams, R., Karousou, R., \& Mackness, J. 2011. Emergent learning and learning ecologies in Web 2.0. In The International Review of Research in Open and Distance Learning, 12(3), 39-59.

Young, J. R. 2012. Inside the Coursera Contract: How an Upstart Company Might Profit from Free Courses, Chronicle of Higher Education. http://www.chronicle.com/article/How-an-UpstartCompany-Might/133065/

Yuan, L., Powell, S. 2013. MOOCs and Open Education: Implications for Higher Education. A White Paper. CETIS. Retrieved March, 21, 2013 from www.publications.cetis.ac.uk/2013/667

Zimmenan, B. \& Schunk, S. 2001. Self-regulated learning and academic achievements: theoretical perspectives (2nd edition). Routledge. 